\title{
Persistência e Abrangência dos Eventos Extremos de Precipitação no Sul do Brasil: Variabilidade Espacial e Padrões Atmosféricos
}

\author{
Camila de Souza Cardoso $^{1}$ (D), Mário Francisco Leal de Quadro $^{2}$ (D), Carla Bonetti $^{1}$ \\ 'Departamento de Geociências, Universidade Federal de Santa Catarina, Florianópolis, SC, \\ Brasil. \\ ${ }^{2}$ Instituto Federal de Santa Catarina, Florianópolis, SC, Brasil.
}

Recebido em: 11 de Maio de 2019 - Revisado em: 1 de Julho de 2019 - Aceito em: 2 de Abril de 2020

\begin{abstract}
Resumo
A região Sul do Brasil em função de sua localização geográfica é caracterizada pela diversidade de sistemas meteorológicos que atuam o ano inteiro, resultando em condições adversas de tempo. Este trabalho analisa os eventos extremos de precipitação caracterizando-os conforme sua persistência e abrangência, e os padrões atmosféricos relacionados. $\mathrm{O}$ desenvolvimento de um algoritmo computacional permitiu a identificação e conhecimento da abrangência espacial dos eventos extremos de precipitação, os quais foram classificados em caráter abrangente e não-abrangente, resultando quatro grupos de chuvas identificados conforme os critérios de intensidade, persistência e abrangência. Os resultados mostraram que o verão é a estação preferencial para ocorrência de eventos extremos em todas categorias analisadas e um maior número de eventos ocorre entre o norte do Rio Grande do Sul e o Paraná, e para os casos de Chuva Persistente o litoral de Santa Catarina se mostra uma região favorável a este tipo de evento. Entre os principais processos atmosféricos para ocorrência de eventos extremos com caráter abrangente são a disponibilidade de umidade nas camadas mais baixas da troposfera, juntamente com o jato de altos níveis e um cavado em médios níveis.
\end{abstract}

Palavras-chave: chuva, padrões atmosféricos.

\section{Persistence and Comprehensiveness of Extreme Precipitation Events in the South of Brazil: Space Variability and Atmospheric Patterns}

\begin{abstract}
The southern region of Brazil is characterized, due to its geographical location, by the diversity of meteorological systems operating throughout the year, resulting in adverse weather conditions. This work analyzes the extreme events of precipitation, characterizing them according to their persistence and comprehensiveness, and the related atmospheric patterns. The development of a computational algorithm allowed the identification and knowledge of the spatial comprehensiveness of the extreme precipitation events, which were classified in a comprehensive and noncomprehensive character, resulting in four precipitation groups identified according to the criteria of intensity, persistence and comprehensiveness. The results showed that summer is the preferred season for the occurrence of extreme events in all the analyzed categories, a greater number of events occur between the northern Rio Grande do Sul and Paraná, and for the cases of Persistent Rain, the Santa Catarina coast is a region favorable to this type of event. Among the main atmospheric processes for the occurrence of extreme events with a comprehensive character are the humidity availability in the lower layers of the troposphere, along with jet in high level and a dug in medium levels.
\end{abstract}

Keywords: rainfall, atmospheric patterns.

Autor de correspondência: Camila de Souza Cardoso. E-mail:k_mila_krdoso@hotmail.com. 


\section{Introdução}

A região Sul do Brasil, por sua localização geográfica, destaca-se pela grande variabilidade de sistemas meteorológicos atuantes ao longo do ano, que resultam em condições diversificadas de tempo. Nas últimas décadas, a frequência de eventos meteorológicos extremos vêm chamando a atenção de pesquisadores, que buscam compreender os mecanismos climáticos e atmosféricos associados a tais fenômenos (Teixeira e Satyamurty, 2007; Pscheidt e Grimm, 2009; Lima et al., 2010).

Não há uma definição formal para caracterizar episódios de chuva extrema. Na literatura diferentes critérios são apresentados, e muitas vezes uma mesma definição é aplicada em diferentes escalas temporais e espaciais, bem como, tipo de dado utilizado. Para o Sul do Brasil, Teixeira e Satyamurty (2007) selecionaram 170 episódios de chuva intensa, entre os anos de 1991 e 2001, definindo como um episódio de chuva intensa aquele em que a área da isoieta de $50 \mathrm{~mm} / 24 \mathrm{~h}$, seja de mínimo $10.000 \mathrm{~km}^{2}$. Rodrigues (2015), analisou os eventos persistentes proveniente de chuvas orográficas para o Litoral de Santa Catarina, definindo como um evento extremo de precipitação os casos em que a chuva acumulada de 5 dias consecutivos maior que o limiar $99.5 \%$.

Para região Sudeste do Brasil, Gonçalves (2015) aplicou a técnica dos quantis em dados de precipitação em pontos de grade, separando os eventos conforme sua intensidade e persistência. No recente trabalho de Prieto (2016) os eventos extremos de precipitação de caráter persistente no estado do Rio Grande do Sul foram identificados para um período de 10 anos. Para ambos os autores, o critério utilizado para definição de um evento persistente foi baseado no número de dias consecutivos com chuva e o volume de precipitação mensal.

A variabilidade da precipitação com eventos extremos e, consequente, desastres naturais tem afetado econômica e socialmente a região Sul do Brasil. Marcelino et al. (2014) ao analisar diferentes tipos de desastres naturais que ocorreram em um período de 30 anos (1980-2010) no estado de Santa Catarina verificaram que as inundações graduais são o tipo mais recorrente. Esse fenômeno está associado a presença de sistemas meteorológicos que possuem características estacionárias, resultando em vários dias com chuva persistente na região, e muitas vezes gerando outros tipos de desastres como os escorregamentos, pois o excesso de precipitação por um determinado período satura o solo, gerando condições necessárias ao desencadeamento deste tipo de desastre natural (Marcelino et al., 2014).

As enchentes e/ou inundações trazem prejuízos a agricultura e deixam milhares de desabrigados nas zonas urbanas e rurais de toda região Sul do Brasil. Segundo dados do CEPED (2013) o estado do Rio Grande do Sul foi atingido por 1006 casos de enxurradas e 413 episódios de inundações entre os anos de 1991 e 2012. O estado de Santa Catarina entre os anos de 2000 e 2010 a somatória de prejuízos provocados por inundações são da ordem de dois bilhões de reais ( $\mathrm{R} \$ 2$ bi). Os desastres naturais registrados no estado do Paraná, segundo dados apresentados pelo CEPED (2013a), são menos representativos comparados aos do Rio Grande do Sul e Santa Catarina, e em geral, estão relacionados a movimentos de massa e mais recorrentes nas áreas urbanas, o que torna moradias e seus habitantes vulneráveis aos desastres dessa natureza.

Segundo Bertoni e Tucci (1993) a ocorrência de inundações dependem das características físicas e climatológicas de uma determinada bacia hidrológica, e especialmente a distribuição espacial e temporal da precipitação. As inundações graduais relacionam com períodos prolongados de chuvas contínuas, de caráter persistente, as quais deixam o solo com um volume de água que impedem que o mesmo tenha tempo de drenar, enquanto que as do tipo bruscas relacionam-se com chuvas intensas e concentradas. Além disso, a magnitude das inundações e os danos e prejuízos associados, muitas vezes vem acompanhado de outro desastre, como o caso dos escorregamentos, que está associado a abrangência espacial e persistência destes eventos extremos de precipitação.

$\mathrm{Na}$ literatura atual ainda são poucos os trabalhos que abordam a separação dos eventos extremos de precipitação conforme as características da precipitação observada, seja persistente ou concentrado. Conhecer a abrangência de um determinado evento extremo de precipitação, bem como sua persistência, é de grande importância já que identificar as regiões mais suscetíveis a este tipo de fenômeno pode auxiliar os serviços de previsão do tempo, planejamento agrícola, urbano e regional e nas estratégias de adaptações sociais correspondentes. Harnack, Apffel e Cermak (1999) estudaram episódios de chuva intensa para região de New Jersey (EUA - Estados Unidos da América), definindo como critérios o limiar de $51 \mathrm{~mm}$, com duração de um ou dois dias (persistência), e uma abrangência espacial de quatro ou mais pontos de grade adjacentes (aproximadamente $10.000 \mathrm{~km}^{2}$ ). Segundo os autores, a seleção desta cobertura espacial exclui da análise eventos convectivos isolados e sistemas sinóti$\cos$ fracos. Pioneiramente, a abrangência dos eventos extremos no Sul do Brasil foi analisada no estudo de Prieto (2016), que considerou um evento abrangente aquele que ocorre em pelo menos 5 estações meteorológicas estudadas que representa cerca de $30 \%$ das estações analisadas. Diante disso, o objetivo deste trabalho é identificar os eventos extremos de precipitação no Sul do Brasil, considerando sua persistência e abrangência espacial, e adicionalmente, determinar os padrões atmosféricos relacionados. 


\section{Material e Métodos}

Para identificação dos eventos extremos de precipitação foram utilizados dados de precipitação diária proveniente do CPC/NCEP (Climate Prediction Center) National Centers for Environmental Prediction) para o período entre 01 de janeiro de 1979 e 31 de dezembro de 2015, totalizando 37 anos (13514 dias) de dados. Os dados de precipitação do CPC/NCEP são baseados num conjunto de pluviômetros, que combina dados de mais de 30.000 estações ao redor do globo utilizando a técnica de Interpolação Ótima (Gandin, 1965), a qual considera a orografia. Este conjunto de dados estão disposto em pontos de grade, e apresentam uma resolução espacial de $0,5^{\circ} \times 0,5^{\circ}$ sobre o globo, desde 1979 até o presente. O período de acumulação diária varia dependendo da região ao redor do globo, sendo que para os países da América do Sul a precipitação diária é considerada entre as $12 \mathrm{UTC}$ do dia $0 \mathrm{e}$ 12UTC do dia 1 (Silva et al. 2007). Cardoso e Quadro (2017) avaliaram o desempenho dos dados de precipitação do CPC/NCEP, como etapa inicial deste estudo e mostraram que o conjunto de dados de precipitação do $\mathrm{CPC} /$ NCEP, comparado com dados de estações pluviométricas, apresenta bom desempenho na representação da precipitação no Sul do Brasil, com tendência a subestimar a precipitação em regiões montanhosas e as diferenças mais significativas ocorrendo apenas em algumas áreas do oeste e litoral do Sul do Brasil.

Para identificação dos eventos extremos foram definidos critérios e condições, os quais foram aplicados as séries diárias de precipitação, obtendo assim dois conjuntos principais:

a. Chuva Intensa, chamada de $\boldsymbol{C I}$ - quando o valor de precipitação diária for maior ou igual ao valor do quantil 99\%, conforme Eq. (1):

$$
C I=P_{d} \geq q_{n}(0.99)
$$

b. Chuva Persistente, chamada de $\boldsymbol{C P}$ - quando o valor de precipitação diária for maior que $1 \mathrm{~mm}$ em pelo menos 3 dias consecutivos, e a média móvel de três dias acima do quantil 99\% (Eq. (2)).

$$
C P=\frac{1}{n} \sum_{i=1}^{n=3} P_{d_{(t-n-1)}} \geq q_{n}(0.99)
$$

onde $P_{(d)}$ representa a precipitação diária no ponto de grade e $q_{(n)}(0.99)$ Representa o quantil 99\% dos dados diários para o período analisado.

Em cada ponto de grade selecionado, analisou-se o quantil sazonal $99 \%$ da série total de dados diários, considerando como estação de Verão os meses de DezembroJaneiro-Fevereiro, Outono os meses de Março-AbrilMaio, Inverno os meses Junho-Julho-Agosto e Primavera os meses de Setembro-Outubro-Novembro, constituindo quatro limiares diferentes. Cada evento identificado é considerado um caso de $C I$ e $C P$.

Para determinação da abrangência espacial dos eventos extremos associados a $C I$ e $C P$ foi desenvolvido um programa (algoritmo) em linguagem Fortran que calcula a abrangência espacial dos eventos extremos $C I$ e $C P$ identificados. $O$ algoritmo baseia-se na obtenção do número de pontos de grade adjacentes ou na vizinhança do ponto que se enquadrou dentro dos critérios de $C I$ e $C P$ obtendo assim a abrangência espacial de cada evento extremo de chuva identificado. A matriz de pontos de grade de rastreio do algoritmo é composta por 63 pontos dispostos conforme a matriz P9x7. A Fig. 1 ilustra a abrangência espacial identificada num caso de chuva intensa ocorrido no dia 28 de setembro de 2009 entre os estados de Santa Catarina e norte do Rio Grande do Sul, com acumulado diário em torno de $100 \mathrm{~mm}$ na mesorregião Serrana (SC).

O critério de determinação de um evento extremo abrangente ou não abrangente foi baseado no cálculo da média do número de pontos de grade dos eventos de precipitação $C I$ e $C P$, rastreados através do algoritmo computacional, para cada estação do ano, obtendo-se assim 8 limiares diferentes, os quais são apresentados na Tabela 1.

Para obtenção dos padrões atmosféricos foram utilizados dados da nova geração de reanálise do ECMWF, Era-interim. O ERA-Interim é um produto de reanálise

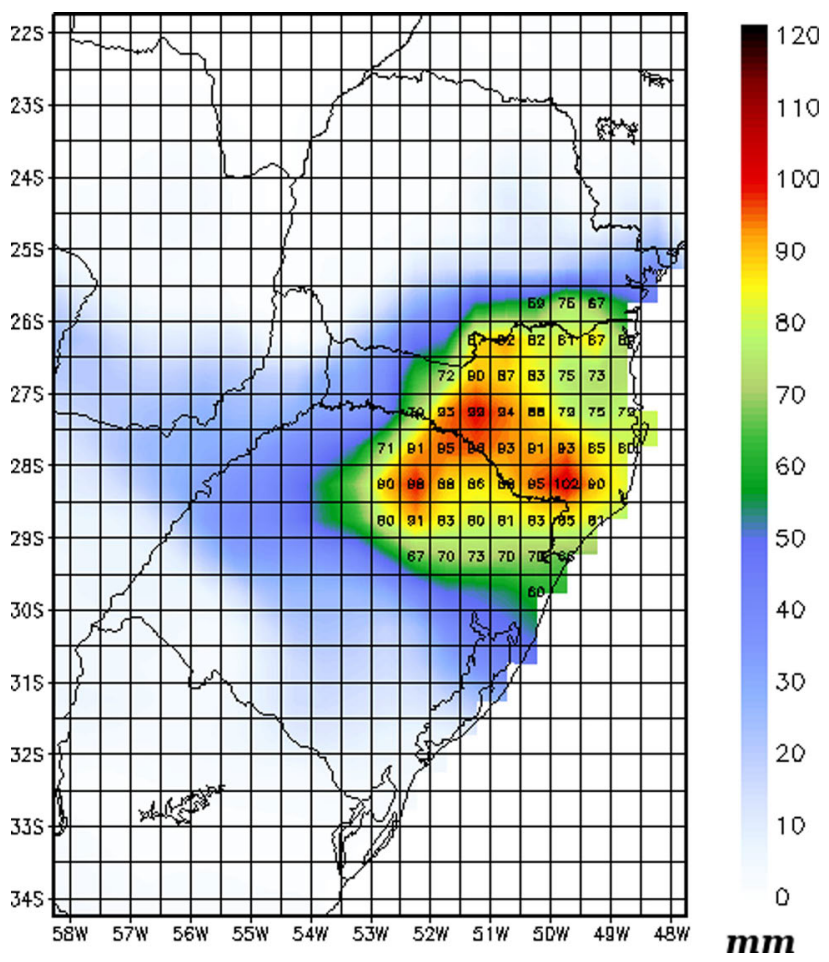

Figura 1 - Precipitação diária acumulada $\left(\mathrm{mm} \mathrm{dia}^{-1}\right)$ para o dia 28 de Setembro de 2009. Os valores representam os pontos de grade que o programa identificou um caso de chuva intensa e abrangente (CIA). 
Tabela 1 - Limiares de abrangência adotados, com base na média do número de pontos de grade.

\begin{tabular}{lcc}
\hline & Chuva Intensa - CI & Chuva Persistente - CP \\
\hline Verão & 5 & 3 \\
Outono & 6 & 6 \\
Inverno & 6 & 4 \\
Primavera & 6 & 2 \\
\hline
\end{tabular}

atmosférica global produzido pelo ECMWF, que foi conduzido com intuito de preparar uma nova geração de reanálises atmosféricas para substituir o ERA-40. Esse conjunto de dados está em constante atualização para que seu conjunto de dados para que seja estendido de até metade do século XX (Dee et al., 2011), aumentando assim a base de dados para o tempo passado. Atualmente $o$ conjunto de dados cobre o período a partir de 1 de janeiro de 1979 até o presente, possuindo uma grande variedade de produtos em pontos de grade disponíveis a cada 3 horas, descrevendo condições meteorológicas, bem como oceânicas e da superfície da terra, e os parâmetros de ar superior a cada 6 horas, cobrindo a troposfera e estratosfera. O espaçamento de grade é de $0.75^{\circ}$ de latitude/ longitude (Simmons et al., 2007; Dee et al., 2011).

Para isto, foram calculados campos de compostos e anomalia dos compostos das variáveis: pressão ao nível do mar e vento à $10 \mathrm{~m}$, vento e divergência de umidade em 850 e $200 \mathrm{hPa}$, altura geopotencial e movimento vertical ascedente em $500 \mathrm{hPa}$. Para testar a significância estatística das anomalias dos compostos atmosféricos foi realizado o Test-t de Student ao nível de confiança de 95\% (Wilks, 2006).

Os compostos e anomalias dos compostos atmosféricos foram construídos no domínio espacial de $20^{\circ} \mathrm{S}-42^{\circ} \mathrm{S}$, $39^{\circ} \mathrm{W}-66^{\circ} \mathrm{W}$ para os campos de superfície, e $10^{\circ} \mathrm{S}-55^{\circ} \mathrm{S}$, $100^{\circ} \mathrm{W}-20^{\circ} \mathrm{W}$ para os campos de altitude $(850,500 \mathrm{e}$ $200 \mathrm{hPa}$ ).

\section{Resultados}

A aplicação dos critérios de Chuva Intensa $(C I)$ e Chuva Persistente $(C P)$ permitiu identificar 1808 dias (13.4\%) de eventos extremos associados a $C I$ e $135(1 \%)$ associados a $C P$. Esses dois conjuntos principais de eventos foram classificados conforme os limiares de abrangência (Tabela 1), obtendo assim quatro grupos, os de Chuva Intensa Abrangente e Não-abrangente $(C I A$ e $C I N)$ e Chuva Persistente Abrangente e Não-abrangente ( $C P A$ e $C P N)$.

Dos 1808 casos de $C I$ verificou-se que 580 casos são considerados como um evento de chuva intensa e abrangente $(C I A)$, o que representa $32.1 \%$ dos casos identificados entre os anos de 1979 e 2015 (Tabela 2). Analogamente, foram identificados 1228 casos de chuva intensa e não-abrangente $(C I N)$, aproximadamente $68 \%$ dos casos.
Tabela 2 - Quantidade de casos de eventos extremos de precipitação associados a Chuva Intensa Abrangente $(C I A)$, Chuva Intensa Não Abrangente $(C I N)$, Chuva Persistente Abrangente $(C P A)$ e Chuva Persistente Não Abrangente $(C P N)$. O valor percentual (\%) representa a parcela de casos relativa aos casos com $C I$ e $C P$.

\begin{tabular}{|c|c|c|c|c|c|c|c|c|}
\hline & \multicolumn{4}{|c|}{ Chuva abrangente } & \multicolumn{4}{|c|}{ Chuva não abrangente } \\
\hline & CIA & $\%$ & CPA & $\%$ & $\mathrm{CIN}$ & $\%$ & $\mathrm{CPN}$ & $\%$ \\
\hline Verão & 204 & 11.3 & 15 & 11.1 & 424 & 23.5 & 48 & 35.6 \\
\hline Outono & 134 & 7.4 & 7 & 5.2 & 286 & 15.8 & 21 & 15.6 \\
\hline Inverno & 113 & 6.3 & 7 & 5.2 & 218 & 12.1 & 19 & 14.1 \\
\hline Primavera & 129 & 7.1 & 10 & 7.4 & 300 & 16.6 & 8 & 5.9 \\
\hline Total & 580 & 32.1 & 39 & 28.9 & 1228 & 67.9 & 96 & 71.1 \\
\hline
\end{tabular}

Nível de significância estatística de 99\%.

A análise sazonal apresentada na Tabela 2 mostra que o maior número de casos com chuva intensa e abrangente (CIA) ocorre no verão, com 204 casos, e 424 casos com chuva intensa não abrangente $(C I N)$. O inverno é a estação do ano com o menor número de casos, e a diferença entre o número de casos com $C I N$ entre verão e inverno é de aproximadamente $50 \%$, ou seja, no verão ocorre praticamente o dobro de casos de CIN comparado ao inverno.

Nos eventos associados a $C P$ verificou-se que dos 135 casos cerca de $28.9 \%$ (39 casos) foram classificados como evento de chuva persistente e abrangente (CPA), e 96 casos (71.1\%) foram considerados como persistente e não abrangente $(C P N)$. Assim como no grupo das chuvas intensas $C I$, o maior número de casos com $C P$ é observado no verão com 15 casos de $C P A$ e $48 C P N$. As estações de outono e inverno apresentam o menor número de casos com $C P A$, com 7 casos, no grupo de $C P N$ a estação da primavera é que apresenta o menor número de casos, com 8 casos (Tabela 2).

Apesar da grande variabilidade temporal dos eventos extremos para as quatro categorias avaliadas, percebe-se que o verão é a estação preferencial para ocorrência. A menor frequência é encontrada durante o inverno, com destaque o mês de agosto (grupos CIN, CIA). Resultados semelhantes foram encontrados por Nunes e Silva (2013) e Rodrigues (2015) que analisaram eventos de precipitação de caráter persistente e propícios a ocorrência de inundações, encontrando um maior número de casos no setor leste de SC durante os meses de verão.

A Fig. 2 mostra a distribuição espacial do número de casos CIA, CIN, CPA e $C P N$ e através dela é possível identificar as regiões do Sul do Brasil em que os eventos extremos de chuva ocorrem com maior frequência. Para os casos de chuva intensa $(C I)$ o número de casos ocorre de forma bem distribuída no Sul do Brasil, com um maior número de casos com CIN (Fig. 2a) no litoral norte de Santa Catarina (leste da mesorregião Norte catarinense) e no Litoral Paranaense, para os casos de CIA (Fig. 2b) apresenta a maior frequência de ocorrência localizado na 

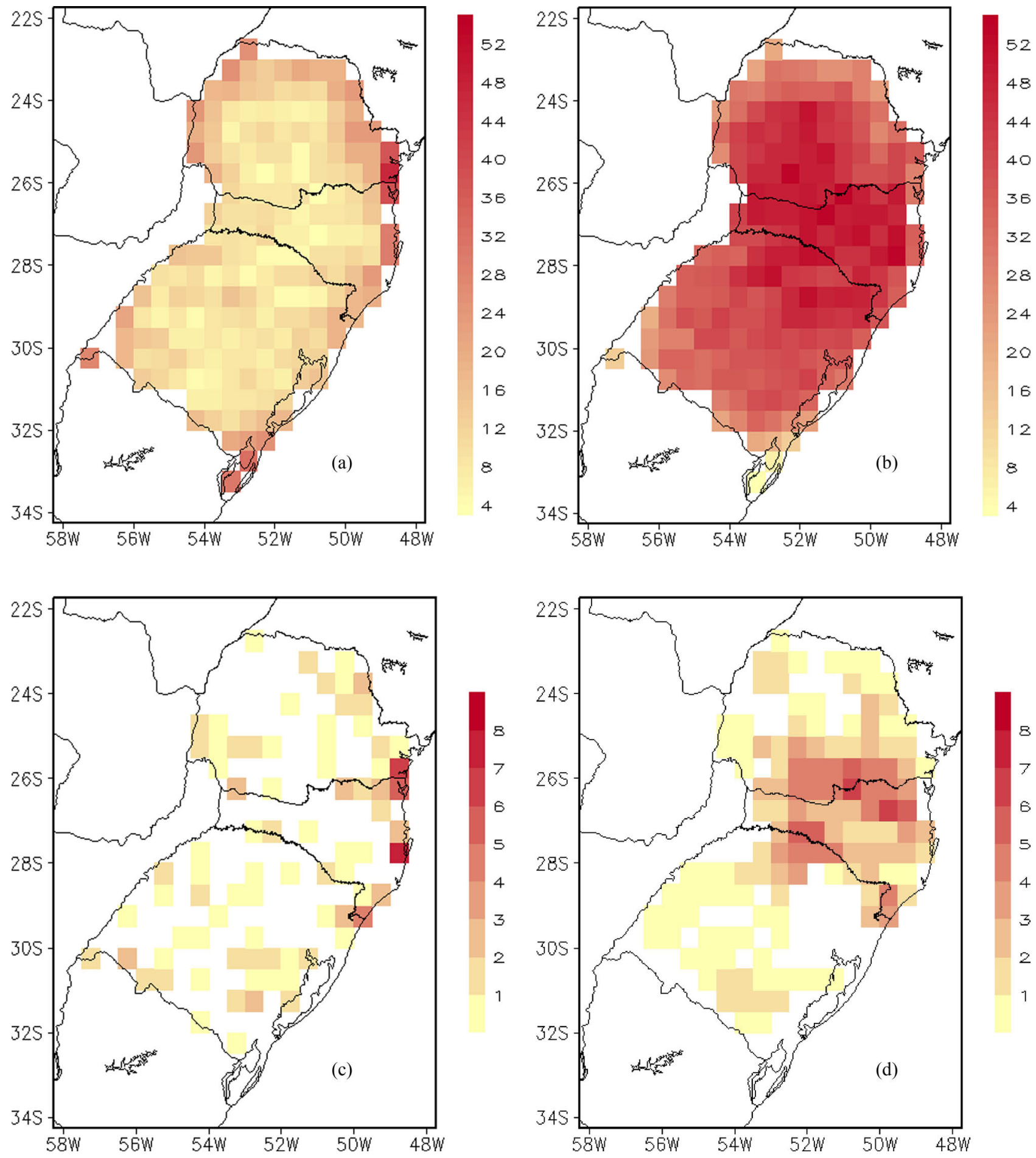

Figura 2 - Distribuição espacial o número de casos com eventos extremos associados a (a) $C I N$, (b) $C I A$, (c) $C P N$ e (d) $C P A$.

região central do Paraná, estado de Santa Catarina e norte do Rio Grande do Sul, aproximadamente entre as latitudes $25^{\circ} \mathrm{S}$ e $29^{\circ} \mathrm{S}$. A frequência de casos com chuva persistente $(C P)$ em eventos extremos associados a $C P N$ (Fig. 2c) ocorrem isoladamente no Sul do Brasil, com má distribuição espacial, e em maior número na Grande Flo- rianópolis e litoral norte de SC e litoral sul do Paraná, os quais ocorrem especialmente no verão. Para os eventos associados a CPA (Fig. 2d) a região preferencial de ocorrência fica localizada entre o norte do Rio Grande do Sul e sul do Paraná, atingindo boa parte do estado de SC, sendo que na primavera esses eventos ocorrem especialmente no 
litoral sul de SC, e no verão nas mesorregiões do Planalto Catarinense e região Serrana do Paraná.

$\mathrm{O}$ volume médio de precipitação estimado nos eventos extremos associados a $C I A, C I N, C P A$ e $C P N$, são apresentados na Fig. 3. Ao comparar a abrangência dos eventos de chuva intensa, CIN e CIA, a maior média de precipitação ocorre, em ambos os casos, nas mesorregiões do Sudoeste Riograndense, Centro-Ocidental Rio-grandense e oeste da mesorregião Noroeste Rio-grandense, com volume mais significativo nos casos de CIA (Fig. 3a e Fig. 3b). Nos eventos extremos associados a chuvas persistente e abrangente $(C P A)$, as média de precipitação diária é observada entre as mesorregiões sudeste e sudoeste do Rio Grande do Sul (Fig. 3d), região que apresentou menor frequência de casos com $C P A$. Nos eventos associados a $C P N$ (Fig. 3c) a precipitação diária média apresenta volumes semelhantes nos pontos de grade em que houve registro da mesma.
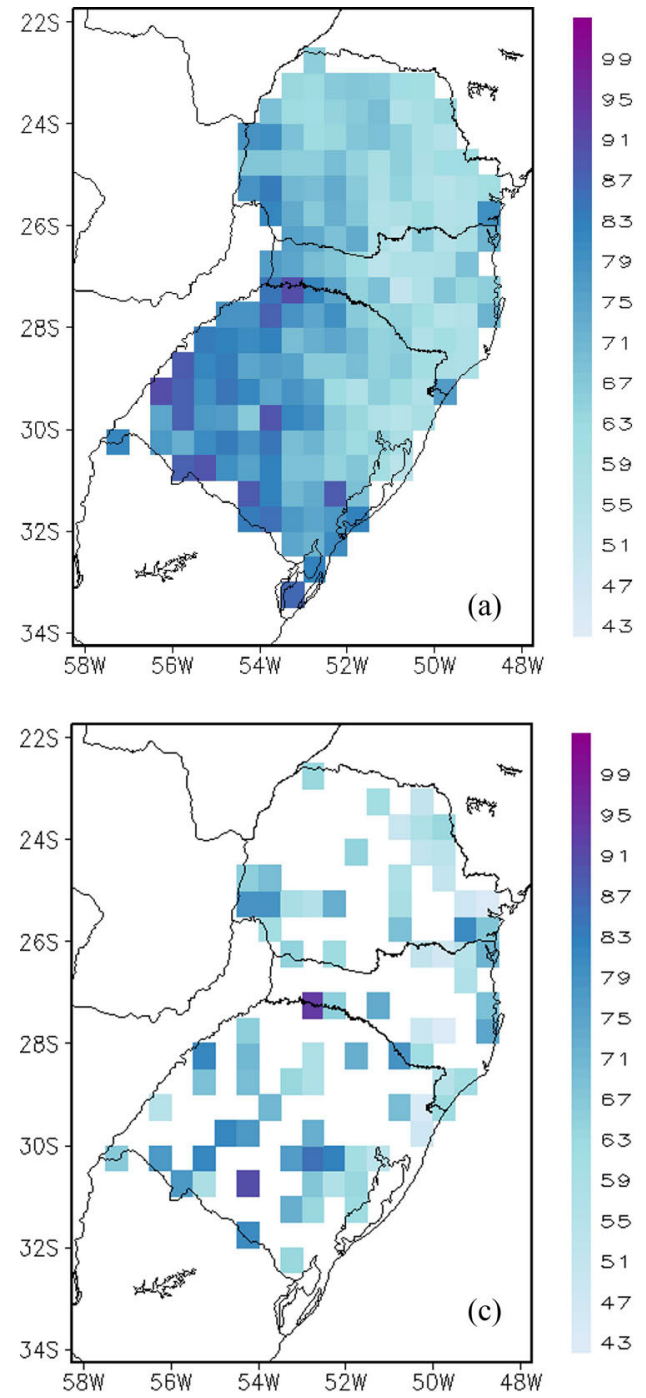

A análise dos padrões atmosféricos foi elaborada para os quatro grupos de eventos extremos identificados, com intuito de compreender as diferenças na configuração atmosférica existente para as diferentes classes de precipitação extrema, conforme sua persistência e abrangência.

Em superfície, similaridades podem ser observadas nos compostos e anomalias dos campos de pressão ao nível médio do mar (PNMM) para os quatro grupos de eventos extremos no Sul do Brasil, onde para todos os casos houve a presença de anomalias negativas de PNMM, associadas a um centro de baixa pressão na região do Paraguai (Fig. 4) e um cavado sobre o Rio Grande do Sul. Por outro lado, as principais diferenças são encontradas na intensidade das anomalias negativas e a extensão do cavado associado ao centro de baixa pressão no Paraguai.

As diferenças entre os compostos anômalos entre os quatro grupos de extremos de precipitação são evidentes,
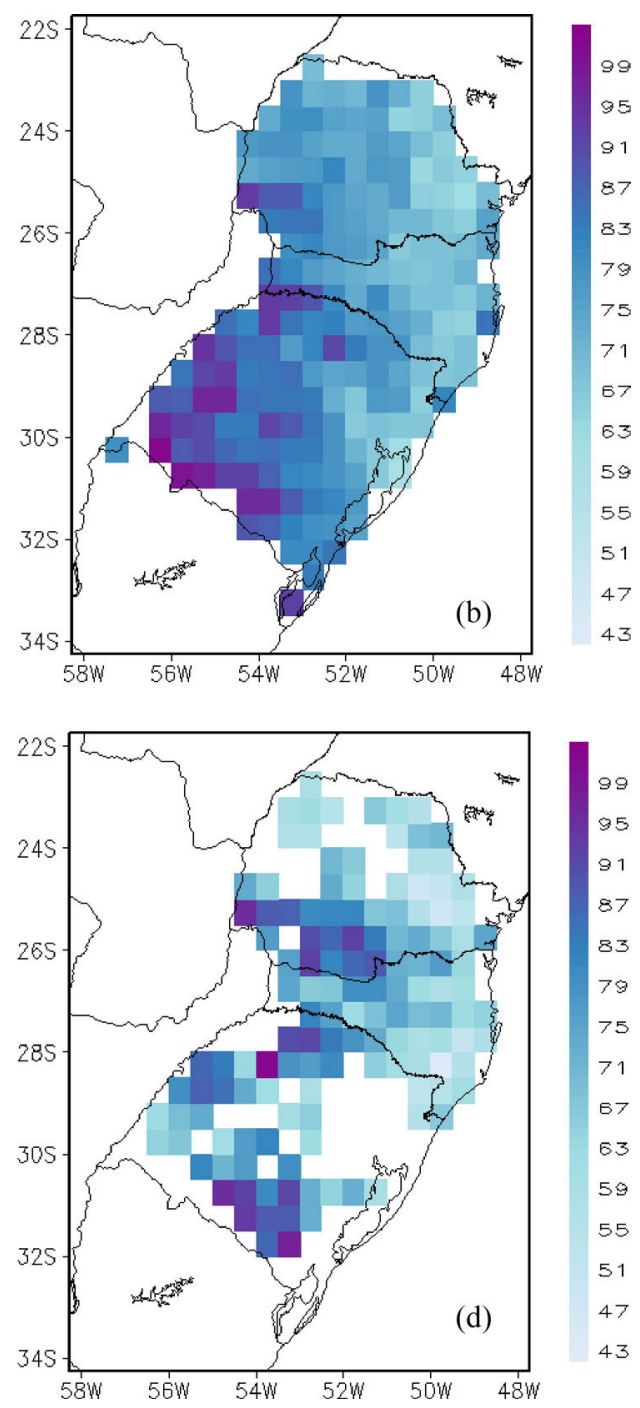

Figura 3 - Precipitação média (mm.dia ${ }^{-1}$ ) em eventos extremos associados a (a) $C I N$, (b) $C I A$, (c) $C P N$ e (d) CPA. 


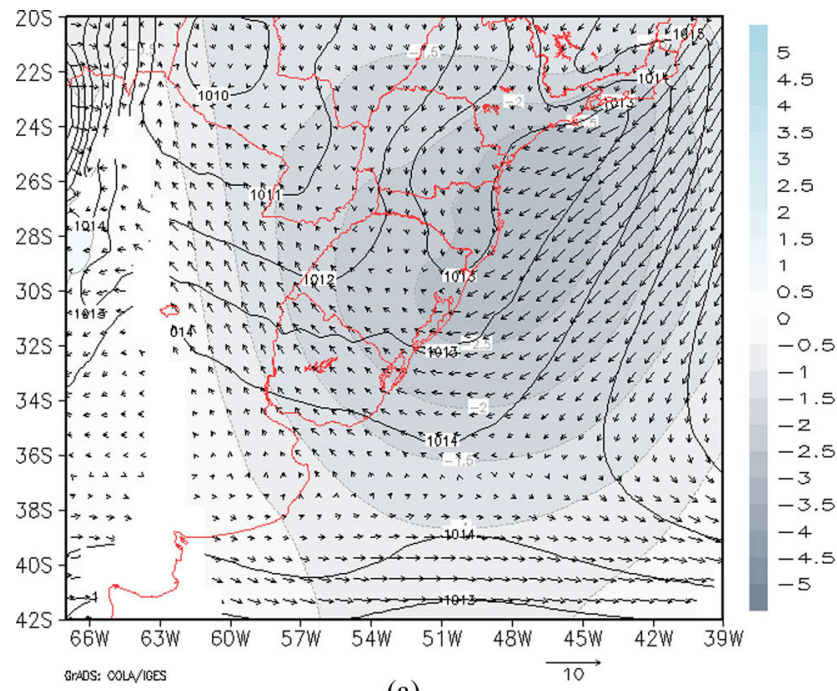

(a)

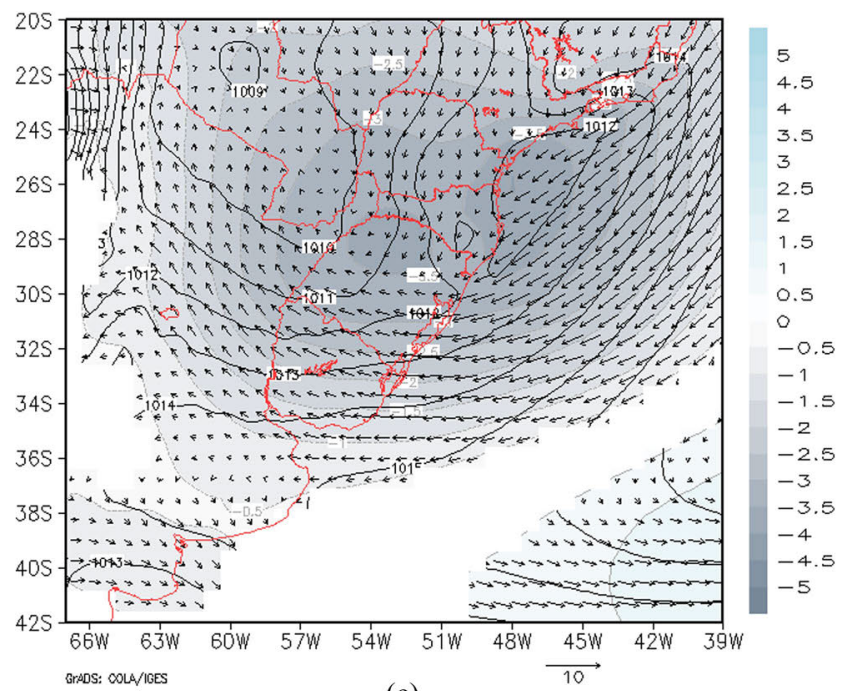

(c)

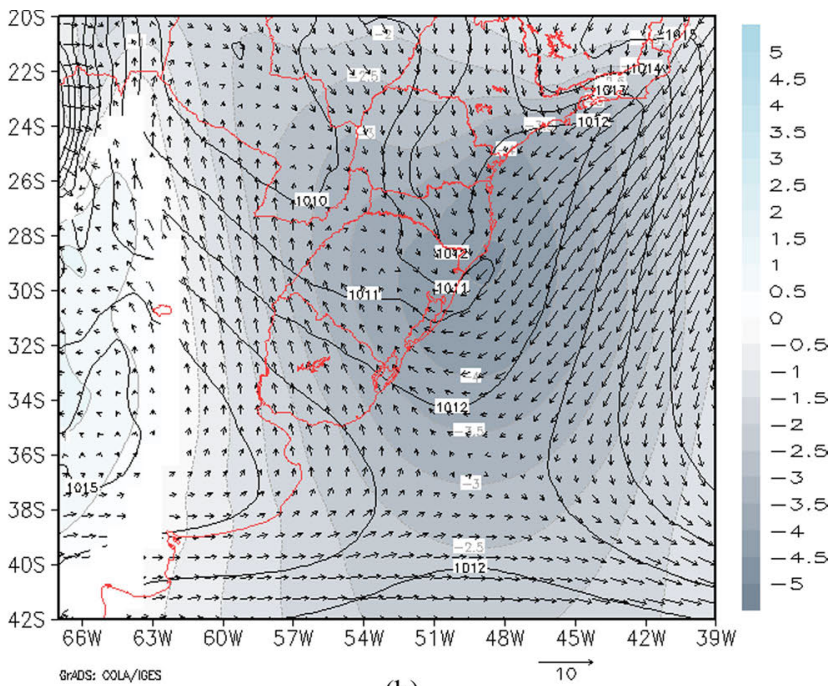

(b)

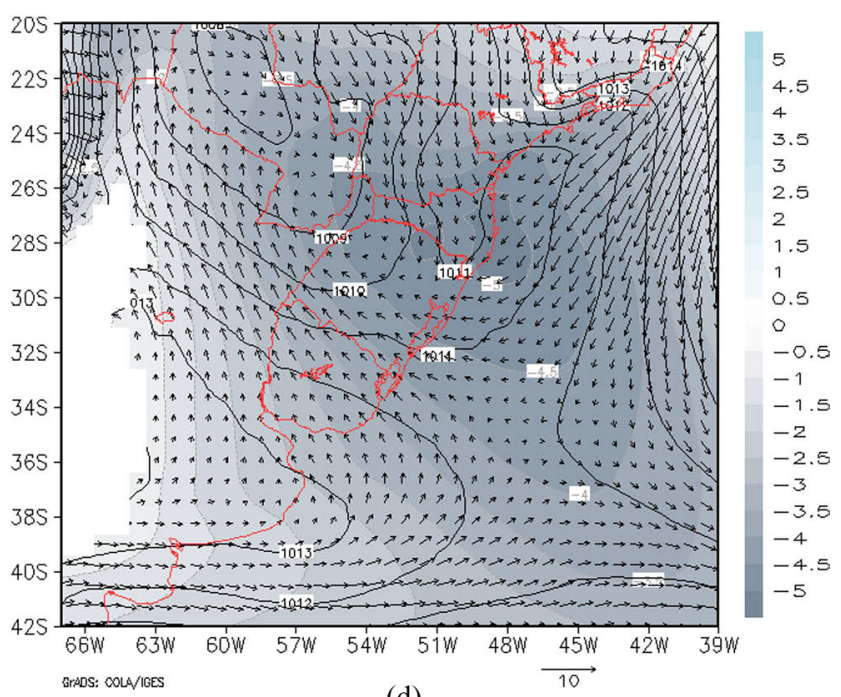

(d)

Figura 4 - Compostos (linhas) e anomalia dos compostos (cores) de Pressão ao Nível Médio do Mar (PNMM, em $h P a$ ) e compostos do vento médio a $10 \mathrm{~m}$ (vetores) para (a) $C I N$, (b) $C I A$, (c) $C P N$ e (d) $C P A$. As anomalias são mostradas ao nível de significância estatística de $95 \%$.

com destaque para os casos de eventos extremos abrangentes, onde a anomalia negativa é da ordem de $-4 \mathrm{hPa}$ para CIA (Fig. 4b) e $-5 \mathrm{hPa}$ para CPA (Fig. 4d). Este padrão mostra a maior intensidade do sistema de baixa pressão nos eventos abrangentes. Ao comparar os casos de chuva não-abrangente, a intensidade da anomalia negativa é da ordem de $-2 \mathrm{hPa}$ e $-3 \mathrm{hPa}$, para $C I N$ (Fig. 4a) e $C P N$ (Fig. 4c), respectivamente.

Ainda em superfície, ao analisar os compostos de vento médio a $10 \mathrm{~m}$ nota-se a presença de ventos do quadrante nordeste (NE) oriundos da Alta Subtropical do Atlântico Sul (ASAS) que vira para o quadrante leste/ sudeste (E/SE) ao sul da Lagoa dos Patos no RS em todos os casos analisados, esse padrão de vento observado no oceano Atlântico adjacente ao litoral sul do Brasil contribui para a convergência de ventos no interior da região e consequentemente movimento ascendente na região. Nos casos $C I A$ e $C P A$ há uma confluência de ventos na região onde há os máximos de anomalias negativas de PNMM (Fig. 4d e Fig. 4d). Adicionalmente, verifica-se que nos casos abrangentes os ventos em superfície são mais intensos entre o centro do Paraná e centro de Santa Catarina, associados ao maior gradiente de pressão, bem como, maior transporte de calor e umidade do norte do país.

Essa configuração atmosférica de superfície é favorável a formação de nuvens e precipitação, sendo que a intensidade da anomalia negativa de PNMM juntamente com a extensão do cavado com eixo centrado no norte do Rio Grande do Sul está associada a condições mais propícias a ocorrência de tempo chuvoso, e consequentemente mais abrangente. Fato que é demonstrado quando se compara a configuração atmosférica e percebe-se que é coincidente com o maior número de casos de eventos extremos (Fig. 2). 
Os resultados apresentados são semelhantes aos encontrados por Teixeira e Satyamurty (2007) que encontraram um centro de baixa pressão no norte da Argentina em casos de chuva intensa sobre o Sul do Brasil. Lima, Satyamurty e Fernández (2010) ao comparar eventos de chuva intensa com eventos de chuva normal também encontraram um padrão de semelhante no campo de PNMM, ocorrendo diferenças nas intensidade das anomalias, na ordem de -2 e $-2.5 \mathrm{hPa}$.

Ao nível de $850 \mathrm{hPa}$, as anomalias do vento meridional mostram que a presença do Jato de Baixos Níveis (JBN) é evidente nos quatro grupos de eventos extremos, com o fluxo de ventos orientado no sentido noroestesudeste, desde a Bolívia até o norte do Rio grande do Sul, se estendendo pelo oceano Atlântico. A presença do JBN em eventos extremos de chuva é fundamental para manutenção da convecção, devido ao transporte de calor e umidade vindo da região Amazônica, que favorece a convergência de ventos, com formação de nuvens e ocorrência de precipitação (Marengo et al., 2009). A intensi- dade do transporte, visualizada pela anomalia do vento meridional, contribui para intensificação dos sistemas de baixa pressão em superfície. Na Fig. 5 nota-se que nos casos abrangentes (Fig. 5b e Fig. 5d), a intensidade das anomalias do vento meridional, tanto de norte como de sul é mais intensa, quando comparada aos casos não-abrangentes. Ressalta-se que o único padrão distinto é do $C P N$, onde o fluxo é de norte (Fig. 5d).

$\mathrm{O}$ transporte de ar quente e úmido promovido pelo JBN proporciona grande convergência no fluxo de umidade, sendo este um dos ingredientes fundamentais para ocorrência de chuvas extremas. Demostrado através da Fig. 6, o campo de convergência do fluxo de umidade em $850 \mathrm{hPa}$ para os quatro grupos de chuva aqui identificados, mostram que nos eventos de caráter abrangente no sul do Brasil existe a maior disponibilidade de umidade na baixa troposfera, com os máximos de convergência ocorrendo desde o sudoeste do Paraná ao nordeste do Rio Grande do Sul, com destaque para o estado de Santa Catarina (Fig. 6b e Fig. 6d). Nos casos $C I N / C P N$ (Fig. 6a e Fig. 6c), não-

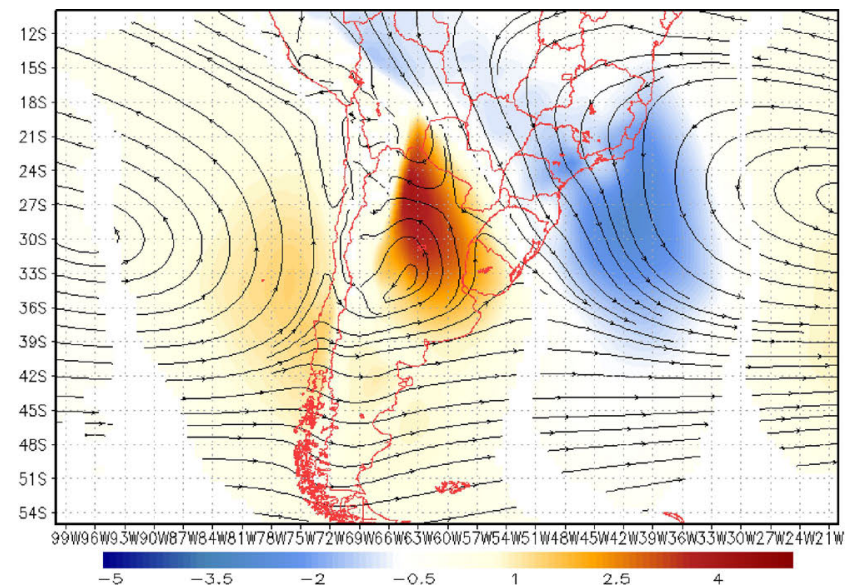

(a)

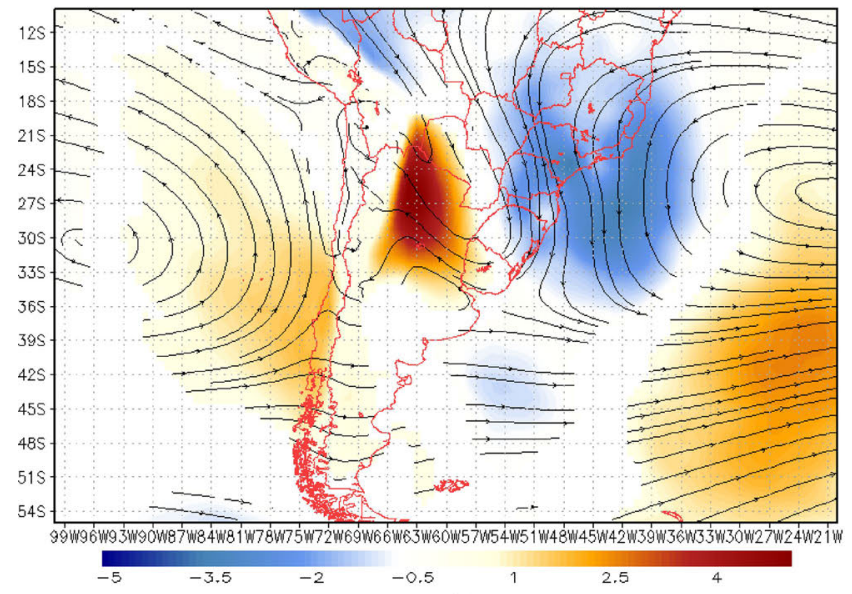

(c)

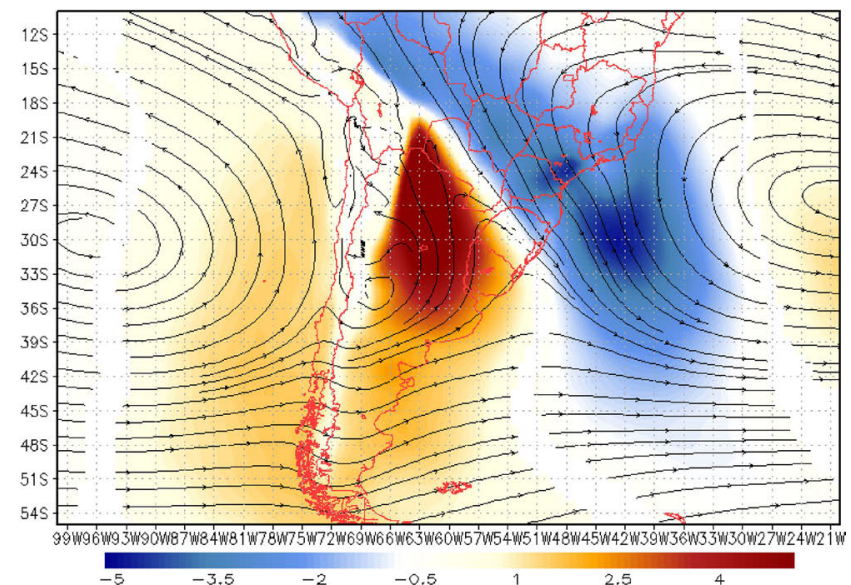

(b)

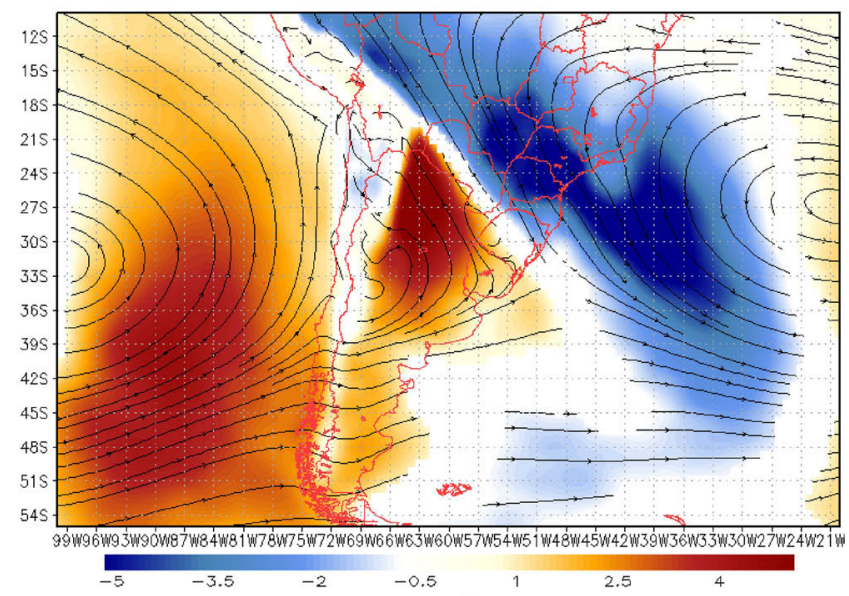

(d)

Figura 5 - Anomalia dos compostos do vento meridional (cores, em ms ${ }^{-1}$ ) e compostos do vento em $850 \mathrm{hPa}$ (linhas) para (a) $C I N$, (b) $C I A$, (c) $C P N$ e (d) CPA. As anomalias são mostradas ao nível de significância estatística de $95 \%$. 


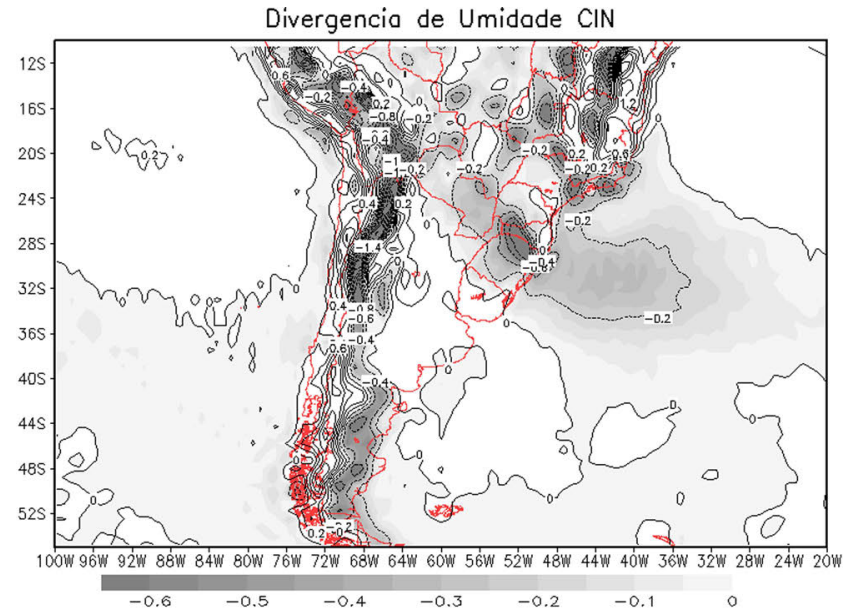

(a)

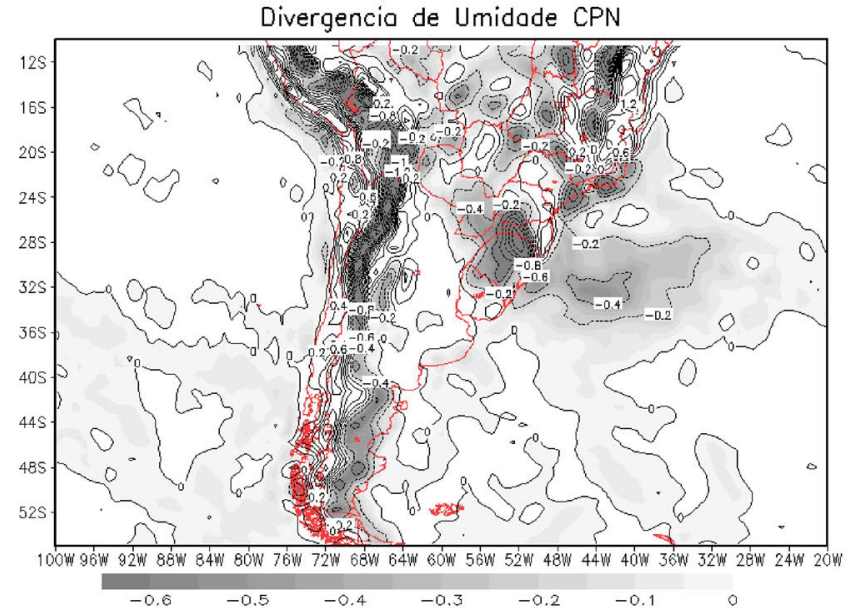

(c)

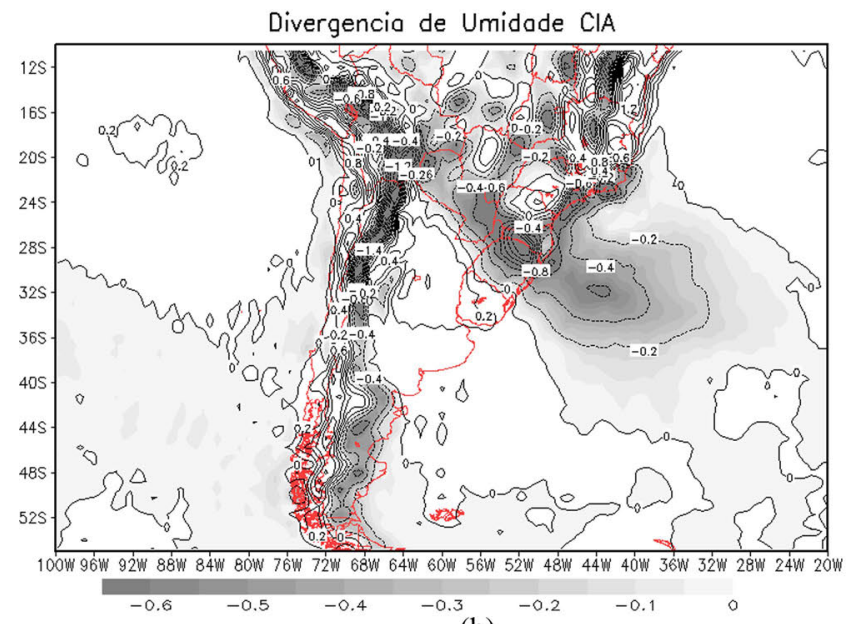

(b)

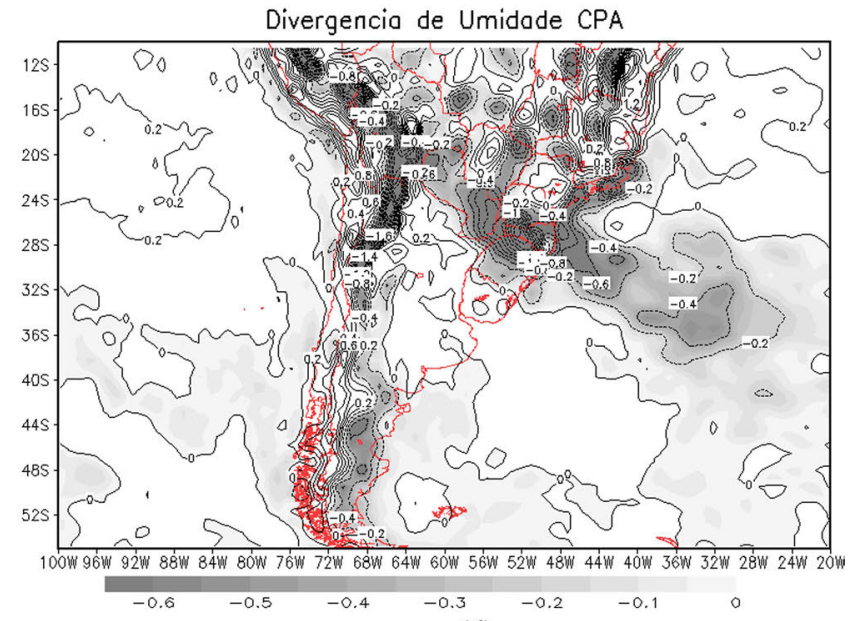

(d)

Figura 6 - Compostos de divergência do fluxo de umidade ao nível de $850 \mathrm{hPa}\left(10^{-7} \mathrm{~s}^{-1}\right)$ para (a) $C I N$, (b) $C I A$, (c) $C P N$ e (d) $C P A$.

abrangentes, embora haja disponibilidade no campo de convergência do fluxo de umidade, esta ocorre com menor intensidade e fica restrita ao estado do RS e oeste de SC e PR.

Ao analisar os campos anômalos fica evidente a configuração distinta entre os grupos abrangentes e nãoabrangentes (Fig. 7), com forte anomalia negativa nos casos de $C P A$, além de um cavado desde o Chile até o litoral sul da Argentina. No grupo de casos CIA (Fig. 7b) também se observa a presença de anomalia negativa de geopotencial, porém com menor intensidade que do grupo CPA (Fig. 7d). No grupo CPA o cavado de médios níveis da atmosfera (Fig. 7d), com escoamento baroclínico, localizado a oeste da região Sul do Brasil está associado a maior disponibilidade de energia e vorticidade ciclônica impulsionado pela forte anomalia no campo de vento em baixos níveis (Fig. 6d), evidenciando o intenso fluxo de ventos quente e úmido oriundos da região Amazônica, os quais desenvolvem a instabilidade necessária para ocorrência de chuvas neste caráter. Este padrão não é observado nos campos não abrangentes Fig. 7a e Fig. 7c).
Essa relação demonstra a importância da intensidade do cavado de médios níveis para caracterizar um evento intenso ou persistente, já que a intensidade da anomalia reflete na intensificação dos sistemas de baixa pressão em superfície e, como consequência, maior instabilidade e condição favorável a chuva extrema em áreas mais abrangentes. A Fig. 8 apresenta os compostos atmosféricos do campo de movimento vertical (ômega) ao nível de $500 \mathrm{hPa}$, sendo exibidos somente valores negativos (movimento ascendente) que, associados a convergência do fluxo de umidade na baixa troposfera, contribuem significativamente para manutenção da convecção e de volumes elevados de precipitação.

Verifica-se nos grupos CIA/CPA (abrangentes), que a intensidade do movimento vertical ascendente é bem evidenciada quando comparado aos não-abrangentes (CIN/ $C P N$ ), com seus máximos concentrados entre Santa Catarina e norte do Rio Grande do Sul (Fig. 8b e Fig. 8d). Em conformidade com as figuras anteriores, a região de maior ascendência de ar está relacionada com a maior disponibilidade de umidade em baixos níveis (Fig. 6), resultando 


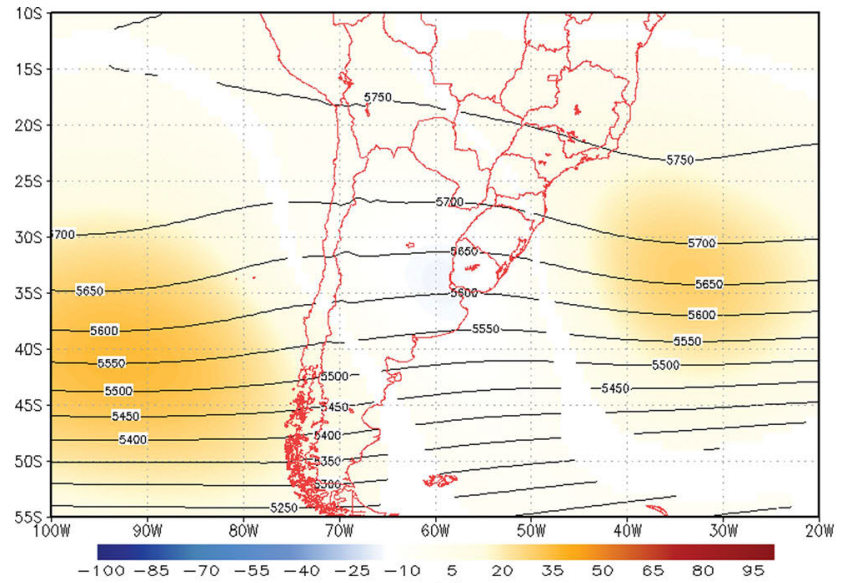

(a)

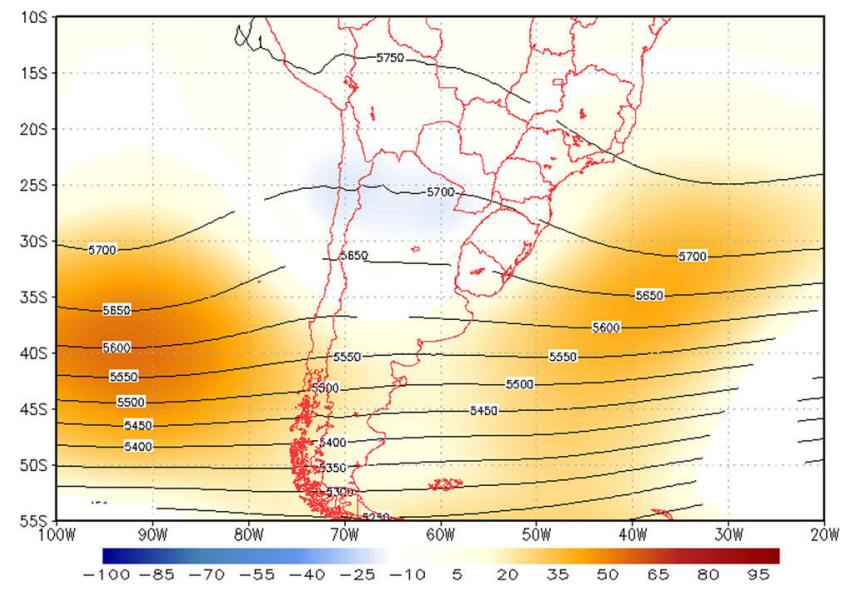

(c)

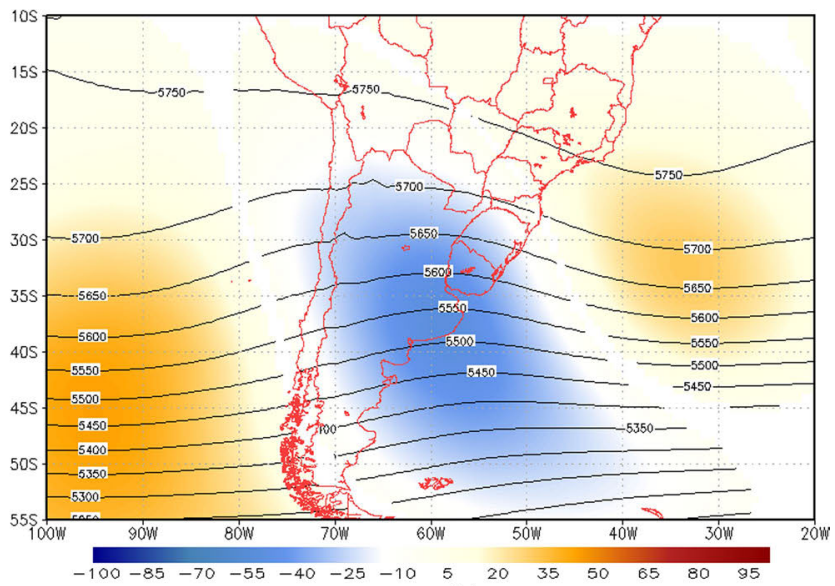

(b)

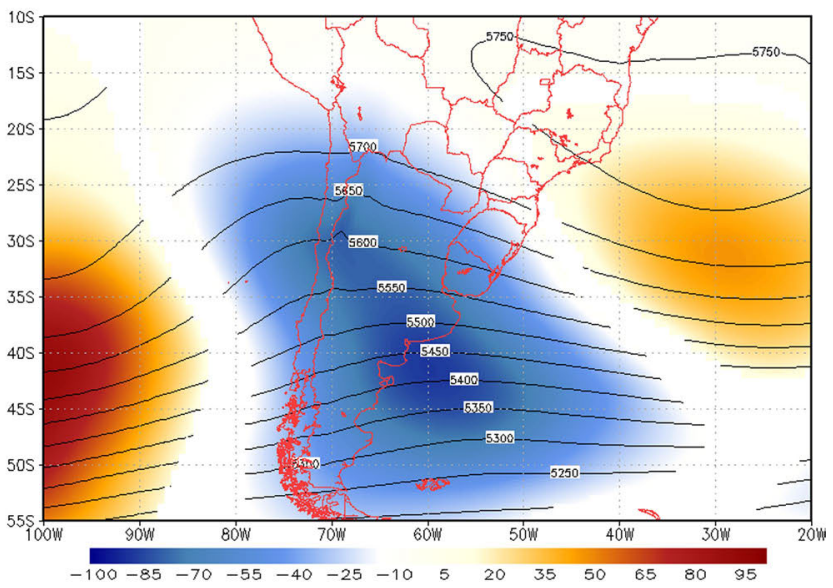

(d)

Figura 7 - Compostos (linhas) e anomalias dos compostos de geopotencial (cores, em m) em 500 hPa para (a) CIN, (b) CIA, (c) CPN e (d) CPA. As anomalias são mostradas ao nível de significância estatística de $95 \%$.

em condições favoráveis a chuvas extremas de caráter abrangente.

A análise do vento zonal ao nível de $200 \mathrm{hPa}$ é utilizada para identificar a intensidade e posicionamento dos jato de altos níveis da atmosfera. Para Escobar (2009) o Jato Polar exerce influência direta ou indireta sobre as mudanças de tempo, já que seus movimentos orientam os sistemas atmosféricos de superfície. Kousky e Cavalcanti (1984) em seu estudo ressaltam o papel do Jato Subtropical nas intensas precipitações ocorridas sobre a região Sul do Brasil durante o evento El Niño de 1983.

A Fig. 9 mostra os compostos do vento e anomalia dos compostos do vento zonal em $200 \mathrm{hPa}$ para os quatro grupos de precipitação analisados. Nesta figura fica evidente as diferenças no escoamento de altos níveis, onde o fluxo de ventos de oeste (anomalia positiva da componente zonal do vento) se mostra mais intensificado nos casos de CPA, refletindo no posicionamento médio dos jatos de altos níveis sobre a região Sul do Brasil. Nos demais grupos apresentados na Fig. 9 a presença dos jatos é verificada com menor intensidade, sendo que para o grupo CIA a anomalia é mais evidente no oceano Atlântico (Fig. 9a).

Em síntese, para os quatro grupos de precipitação verifica-se a importante da presença de um sistema de baixa em superfície, juntamente com uma intensa anomalia ciclônica e a confluência de ventos a $10 \mathrm{~m}$. Na baixa troposfera, o intenso JBN se mostra presente em todos os grupos analisados, contribuindo para a intensa convergência do fluxo de umidade na Região Sul do Brasil. Em médios e altos níveis posicionamento e intensidade do cavado determinam a circulação atmosférica em baixos níveis da atmosfera, já que a divergência que ocorre a leste do eixo do cavado de médios e altos níveis induz a situações de convergência fluxo de umidade e movimentos ascendentes em superfície, favorecendo o desenvolvimento de nuvens profundas e precipitação intensa.

Sugere-se que a intensidade destes padrões troposféricos estão entre os mais importantes processos meteorológicos para manutenção da instabilidade e consequen- 


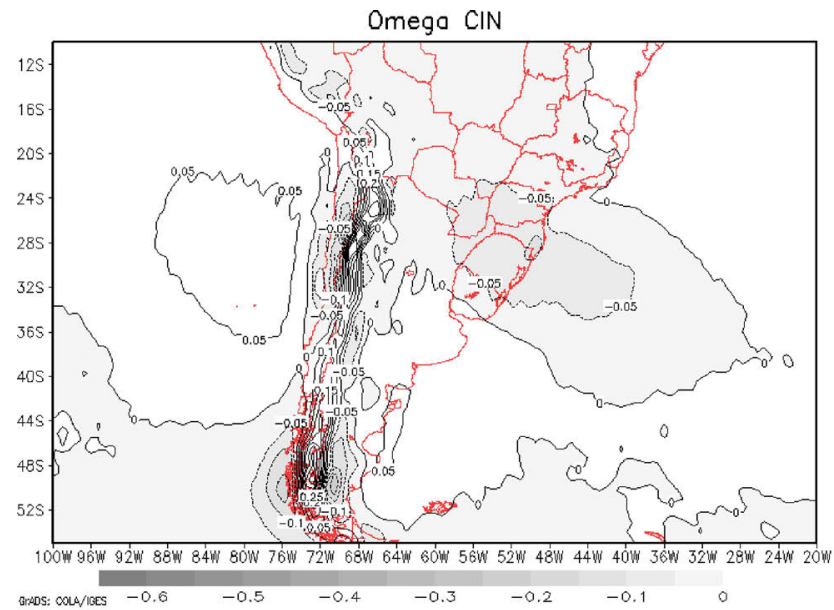

(a)

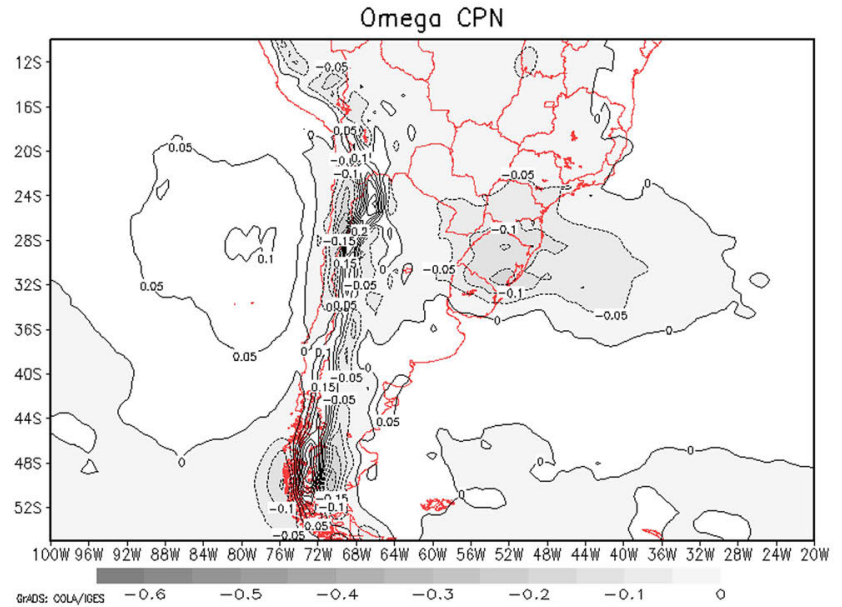

(c)

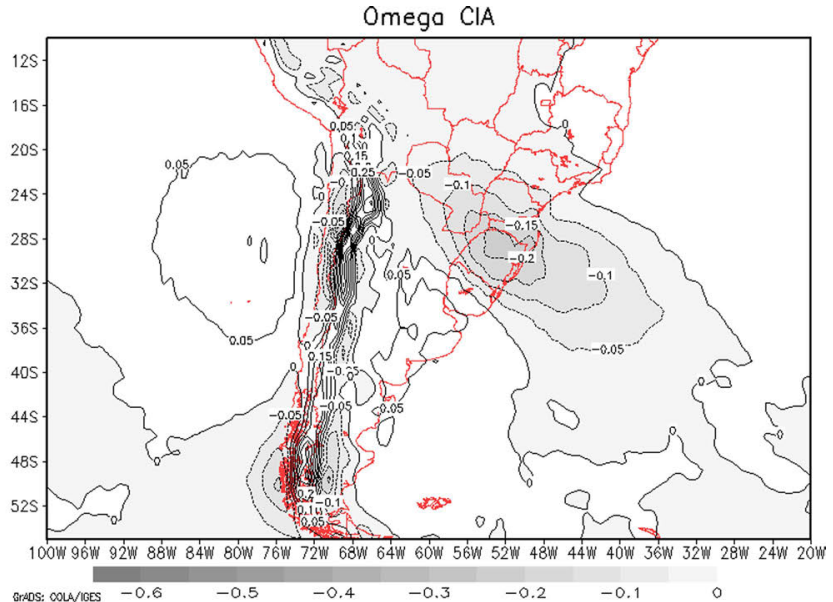

(b)

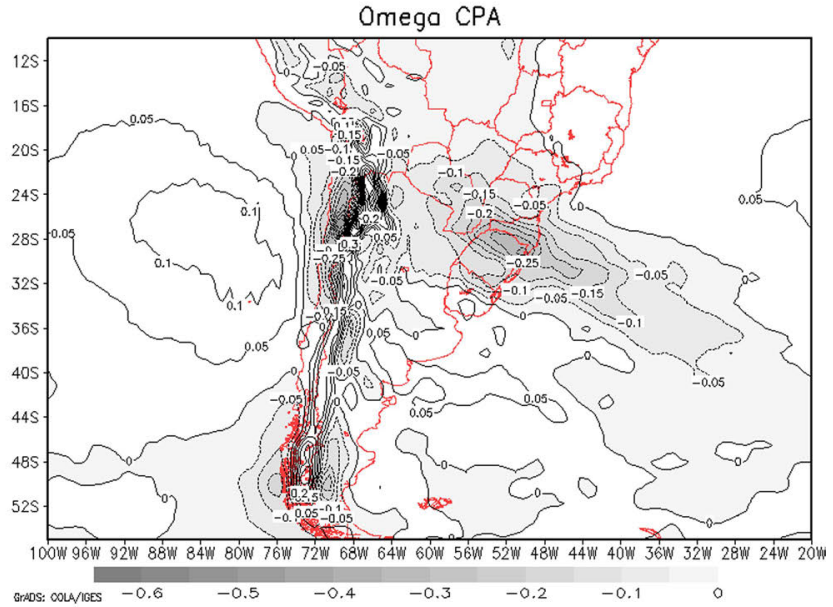

(d)

Figura 8 - Movimento vertical ascendente $\left(\mathrm{Pas}^{-1}\right)$ para (a) $C I N$, (b) $C I A$, (c) $C P N$ e (d) $C P A$. As anomalias são mostradas ao nível de significância estatística de $95 \%$.

temente a determinação de um evento abrangente (mais intenso) e não abrangente (menos intenso). A convergência do fluxo de umidade apresentou um papel importante na abrangência espacial dos eventos $C I / C P$, se mostrando mais intensa e em maior disponibilidade na região Sul do Brasil (Fig. 6b e 6d) nos eventos de caráter abrangente, com destaque para $C P A$.

Nos casos de chuva não-abrangente $(C I N$ e $C P N)$ não se verifica essa característica no escoamento da média e alta troposfera, sugerindo que a intensidade do jato de altos níveis acoplado a um cavado na média troposfera, com forte movimento vertical ascendente e a presença do JBN sejam fundamentais para maior abrangência espacial dos eventos extremos de precipitação. No estudo apresentado por Teixeira e Satyamurty (2007), a presença do cavado em médios níveis da atmosfera $(500 \mathrm{hPa})$ juntamente de forte convergência do fluxo de umidade em baixos níveis e divergência no escoamento de altos níveis são, em termos gerais, ambientes sinóticos favoráveis as chuvas extremas.

\section{Conclusão}

Os eventos extremos de precipitação possuem características sazonais bem definidas, sendo o verão a estação preferencial para ocorrência de eventos extremos nos quatro grupos analisados (CIN/CIA e CPN/CPA) e o inverno a época do ano menos favorável. Resultados semelhantes foram encontrados por Nunes e Silva (2013) e Rodrigues (2015).

As regiões mais favoráveis a ocorrência de eventos de caráter abrangente concentram-se numa faixa entre as latitudes $25^{\circ} \mathrm{S}$ e $29^{\circ} \mathrm{S}$ (entre norte do estado do Rio Grande do Sul e o Paraná). Para os casos classificados como não-abrangentes houve diferenças para os eventos de chuvas Intensas os quais ocorrem preferencialmente no litoral do Paraná, e para os casos de chuvas Persistentes no litoral de Santa Catarina. Adicionalmente, verificou-se que a maior precipitação média destes eventos não está diretamente relacionada ao maior número de casos, já que as mesorregiões sudeste e sudoeste do Rio Grande do Sul, 


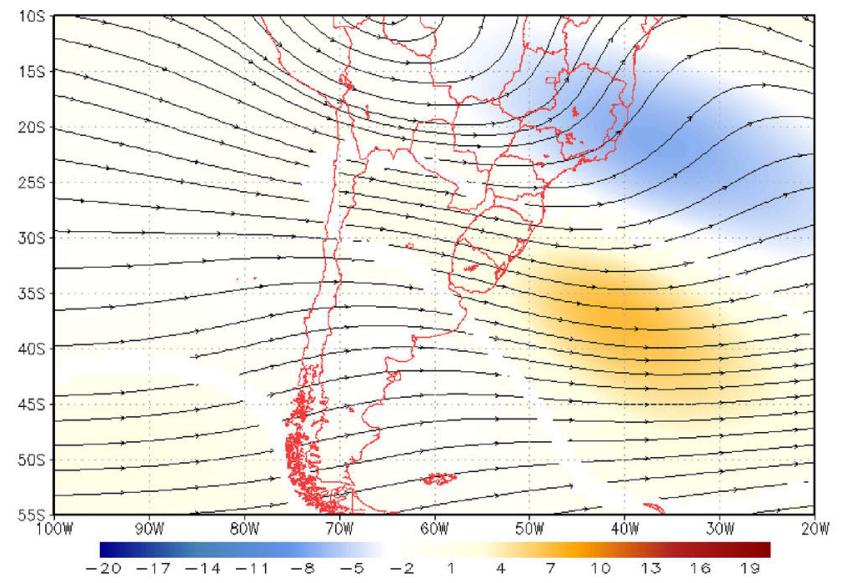

(a)

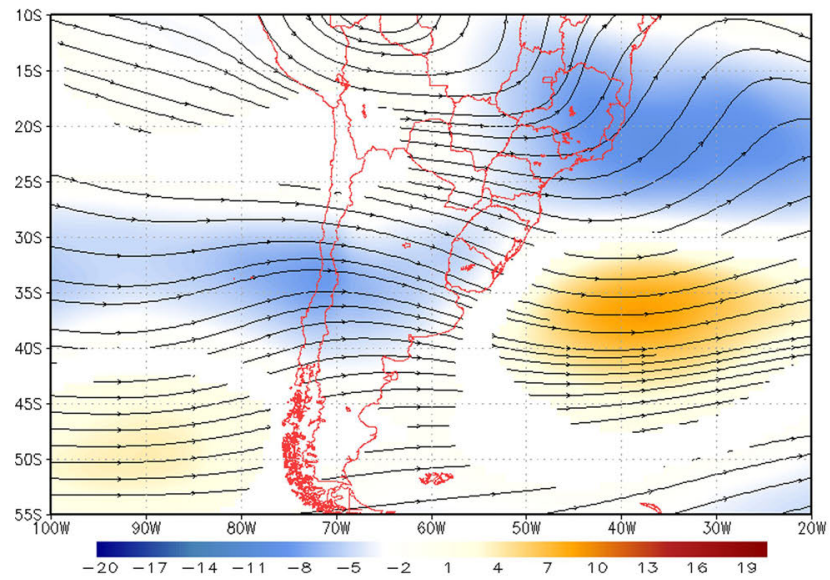

(c)

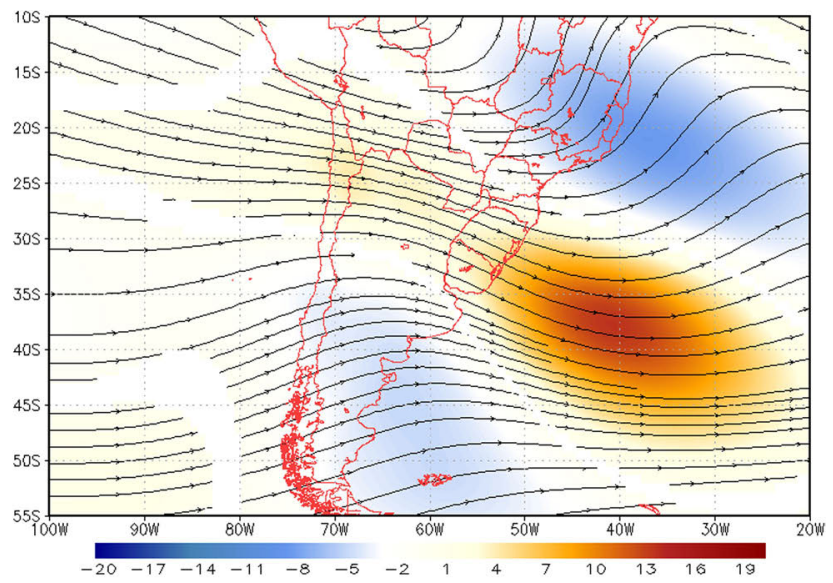

(b)

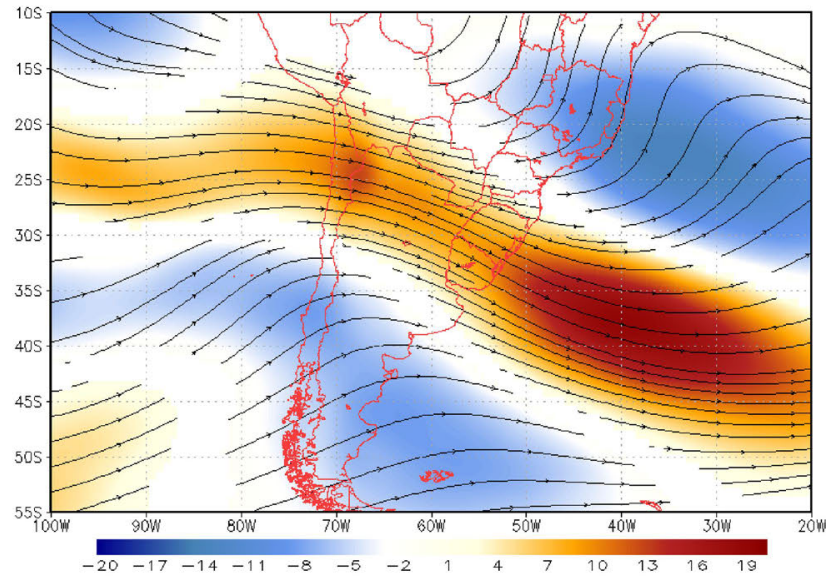

(d)

Figura 9 - Anomalia dos compostos do vento zonal (cores, em ms-1) e compostos do vento em $200 \mathrm{hPa}$ (linhas) para (a) $C I N$, (b) $C I A$, (c) $C P N$ e (d) $C P A$. As anomalias são mostradas ao nível de significância estatística de $95 \%$.

apresentam um menor número de casos com chuva intensa e maior média de precipitação.

Por fim, a análise de compostos atmosféricos e suas anomalias foi aplicada para compreender os mecanismos atmosféricos responsáveis por cada tipo de evento extremo identificado. Para todos grupos analisados houve a presença de um sistema de baixa pressão e o Jato de Baixos Níveis, concordando com o trabalho de Teixeira e Satyamurty (2007). No entanto, a convergência do fluxo de umidade nas camadas mais baixas da troposfera se mostrou ser um dos principais ingredientes atmosféricos para ocorrência de um evento extremo de caráter abrangente, juntamente, com o jato de altos níveis acoplado a um cavado na média troposfera. Essa conjunção de sistemas meteorológicos são fundamentais para manutenção da instabilidade propiciando um ambiente atmosférico mais favorável a ocorrência de um evento extremos de precipitação.

Os resultados apresentados neste trabalho mostraram a complexidade em analisar eventos extremos de precipitação trazendo uma nova abordagem ao distinguir os fenômenos de curta duração, aqui tratados como Intensos, e os de maior duração nomeados como Persistentes, separando-os por sua abrangência espacial. A compreensão destes tipos de eventos e sua espacialização fornece instrumentos para correlacionar os resultados aqui apresentados com diversas áreas do conhecimento, como por exemplo, a comparação entre o número de eventos e a ocorrência de inundações bruscas e graduais, sendo esta uma sugestão para trabalhos futuros. No entanto, ressaltamos que a base de dados de precipitação do CPC apesar de ter bom desempenho em representar a precipitação no Sul do Brasil pode apresentar limitações quando trata-se de chuvas convectivas e em regiões de relevo muito acidentado, como mencionado na avaliação realizada por Cardoso e Quadro (2017), o que pode comprometer os resultados aqui neste tipo de situação.

Considerando a importância do entendimento dos eventos extremos de precipitação e o impacto dos mesmos na sociedade, faz-se necessário uma análise da relação entre as áreas mais favoráveis a ocorrência dos eventos, com fatores econômicos e o crescimento urbano, bem 
como uma reflexão sobre os desastres naturais e os reflexos destes. E assim ter instrumentos para novas perspectivas de políticas públicas, com ampliação da infraestrutura e estratégias de adaptação, com intuito de reduzir os impactos dos eventos extremos e as vulnerabilidades sociais, aumentando a resiliência das regiões e comunidades afetadas.

\section{Agradecimentos}

O primeiro autor agradece ao Programa de Pós-Graduação em Geografia da Universidade Federal de Santa Catarina, ao Programa Demanda Social (DS) da CAPES pelo apoio financeiro durante parte do trabalho, e sua ex-orientadora Prof. ${ }^{\text {a Dr. }}$ a Magaly Mendonça (in Memorian), sendo este trabalho parte de sua tese de Doutorado.

\section{Referências}

CARDOSO, C.S; QUADRO, M.F.L. Análise comparativa de dados de precipitação gerados pelo "Climate Prediction Center - CPC" versus dados observados para o Sul do Brasil. Revista Brasileira de Geografia Física, v. 10, n. 4, p. 1180-1198, 2017.

DEE, D.; UPPALA, S.M.; SIMMONS, A.J.; BERRISFORD, P.; POLI, P.; et al. The era-interim reanalysis: Configuration and performance of the data assimilation system. Quarterly Journal of the Royal Meteorological Society, v. 137, n. 656, p. 553-597, 2011.

ESCOBAR, G. Jatos de Altos Níveis. Tempo e Clima no Brasil. Oficina de Textos, São Paulo, p. 127-34, 2009.

GANDIN, L.S.; HARDIN, R. Objective Analysis of Meteorological Fields. Israel Program for Scientific Translations, Jerusalem, 1965.

GONCALVES, J.P. Caracterização e Variabilidade de Situações Sinóticas Associadas a Episódios de Chuva Intensa e Chuva Persistente Durante a Estação Chuvosa na Região Sudeste do Brasil. Dissertação de Mestrado, Instituto Nacional de Pesquisas Espaciais, 2015. Disponível em: http://urlib.net/sid.inpe.br/mtc-m21b/2015/07.11.04.35. Acesso em 16 maio 2016.
KOUSKY, V.; CAVALCANTI, I. Eventos oscilação sul el niño: características, evolução e anomalias de precipitação. Ciência e Cultura, v. 36, n. 11, p. 1888-1899, 1984.

LIMA, K.C.; SATYAMURTY, P.; FERNÁNDEZ, J.P.R. Largescale atmospheric conditions associated with heavy rainfall episodes in southeast Brazil. Theoretical and Applied Climatology, v. 101, n. 1-2, p.121-135, 2010.

MARENGO, J.A.; AMBRIZZI, T.; SOARES, W.R. Jato de baixos níveis ao longo dos andes. In: Tempo e Clima no Brasil. Oficina de Textos, São Paulo, p. 169-180, 2009.

MARCELINO, I.D.O. Adversidades Atmosféricas no Estado de Santa Catarina no Período de 1980 a 2010. Atlas de Desastres Naturais do Estado de Santa Catarina. Instituto Histórico e Geográfico de Santa Catarina, Florianópolis, p. 13-82, 2014.

NUNES, A.B.; SILVA, G.C. Climatology of extreme rainfall events in eastern and northern Santa Catarina state, Brazil: Present and future climate. Revista Brasileira de Geofísica, v. 31, n. 3, p. 413-425, 2013.

PSCHEIDT, I.; GRIMM, A.M. Frequency of extreme rainfall events in southern Brazil modulated by interannual and interdecadal variability. International Journal of Climatology, v. 29, n. 13, p. 1988-2011, 2009.

PRIETO, R.B. Estudo de Eventos Extremos de Chuva Persistente sobre o Rio Grande do Sul entre 2004 e 2013. Dissertação de Mestrado, Universidade Federal de Pelotas, Programa de Pós-Graduação em Meteorologia, 2016.

RODRIGUES, M.L.G. Eventos de Chuva Orográfica em Santa Catarina: Climatologia e Simulações Numéricas. Tese de Doutorado, Universidade de São Paulo, 2015.

SILVA, V.B. An improved gridded historical daily precipitation analysis for Brazil. Journal of Hydrometeorology, v. 8, n. 4, p. 847-861, 2007.

SIMMONS, A. Era-interim: New ECMWF reanalysis products from 1989 onwards. ECMWF Newsletter, v. 110, n. 110, p. 25-35, 2007.

TEIXEIRA, M.S.; SATYAMURTY, P. Dynamical and synoptic characteristics of heavy rainfall episodes in southern Brazil. Monthly Weather Review, v. 135, n. 2, p. 598-617, 2007.

WILKS, D. Statistical Methods in the Atmospheric Sciences. Elsevier, Amsterdam, 2006.

License information: This is an open-access article distributed under the terms of the Creative Commons Attribution License (type CC-BY), which permits unrestricted use, distribution and reproduction in any medium, provided the original article is properly cited. 